\title{
Response to Letter: The Use of Integra Dermal Regeneration Template versus Flaps for Reconstruction of Full-Thickness Scalp Defects Involving the Calvaria: A Cost-Benefit Analysis
}

\author{
M. Schiavon ${ }^{1} \cdot$ M. Francescon ${ }^{1}$ D. Drigo ${ }^{2}$ G. Salloum ${ }^{1}$. \\ R. Baraziol ${ }^{1} \cdot$ J. Tesei ${ }^{1} \cdot$ E. Fraccalanza ${ }^{1} \cdot$ F. Barbone ${ }^{2}$
}

Received: 8 December 2016/Accepted: 8 December 2016/Published online: 31 January 2017

(C) Springer Science+Business Media New York and International Society of Aesthetic Plastic Surgery 2017

No Level Assigned This journal requires that authors assign a level of evidence to each article. For a full description of these Evidence-Based Medicine ratings, please refer to the Table of Contents or the online Instructions to Authors www.springer.com/00266.

\section{Dear Sir}

Thank you very much for your comment. Indeed, we agree that Integra can be used in many different situations.

Among more than 600 free flaps we have performed, we had no case in which it was impossible to cover the pedicle with soft tissues. Nevertheless, this eventuality could happen when the soft tissues are less present like in the distal third of the lower limbs. To overcome this situation, we always try to raise the pedicle as long as possible to reach the vessels for the anastomosis in the middle third of the leg. We usually perform an end-to-side arterial anastomosis on a good vessel like the posterior tibial or peroneal artery as far away as possible from the damaged area to cover with the flap. Moreover, when we suspect we could face some difficulties in inserting the pedicle in the surrounding tissues, we design the flap specifically so that it presents a prolongation to protect the pedicle allowing for good soft tissue coverage of it. In other occasions, we could also cover the pedicle under a tension-free local skin flap and repair the donor site with a skin graft. Nevertheless, we agree that in similar cases, Integra can be a good option as demonstrated by Leclere et al. [1] and as you suggested.

We would like to thank you again for your valuable suggestion.

\section{Compliance with Ethical Standards}

Conflict of interest The authors declare that they have no conflicts of interest to declare.

\section{Reference}

1. Leclere F, Desnouveaux E, Casoli V (2016) Acellulare dermal matrix: New applications for free flap pedicle coverage: a prospective study in 10 patients. J Cosmet Laser Ther 25:1-12

M. Schiavon

mauro.schiavon@asuiud.sanita.fvg.it

1 Struttura Operativa Complessa di Chirurgia Plastica e Centro Ustioni, Azienda Ospedaliero-Universitaria S. Maria della Misericordia, Udine, Italy

2 Istituto di Igiene ed Epidemiologia Clinica, Azienda Ospedaliero-Universitaria S. Maria della Misericordia, Udine, Italy 